\title{
Relationship between Dietary and Other Lifestyle Habits and Cardiometabolic Risk Factors in Men
}

\author{
Sayuri Katano ${ }^{1}$, Yasuyuki Nakamura ${ }^{1,2^{*}}$, Nagako Okuda ${ }^{3}$, Yoshitaka Murakami ${ }^{4}$, Nagako Chiba ${ }^{5}$, Katsushi Yoshita ${ }^{6}$, \\ Taichiro Tanaka ${ }^{7}$, Junko Tamaki ${ }^{8}$, Toru Takebayashi ${ }^{9}$, Akira Okayama ${ }^{3}$, Katsuyuki Miura ${ }^{2}$, Tomonori Okamura ${ }^{9}$ and \\ Hirotsugu Ueshima², for HIPOP-OHP Research Group
}

\begin{abstract}
Background: Prevalence of men with cardiometabolic risk factors (CMRF) is increasing in Japan. Few studies have comprehensively examined the relation between lifestyles and CMRF.

Methods: We examined the baseline data from 3,498 male workers ages 19 to 69 years who participated in the high-risk and population strategy for occupational health promotion (HIPOP-OHP) study at 12 large-scale companies throughout Japan. The physical activity of each participant was classified according to the International Physical Activity Questionnaire (IPAQ). Dietary intake was surveyed by a semi-quantitative Food Frequency Questionnaire. We defined four CMRF in this study as follows: 1) high blood pressure (BP): systolic BP $\geq 130 \mathrm{mmHg}$, or diastolic BP $\geq 85 \mathrm{mmHg}$, or the use of antihypertensive drugs; 2) dyslipidemia: high-density lipoproteincholesterol concentration $<40 \mathrm{mg} / \mathrm{dl}$, or triglycerides concentration $\geq 150 \mathrm{mg} / \mathrm{dl}$, or on medication for dyslipidemia; 3) impaired glucose tolerance: fasting blood sugar concentration $\geq 110 \mathrm{mg} / \mathrm{dl}$; 4) obese: a body mass index $\geq 25 \mathrm{~kg} / \mathrm{m}^{2}$.

Results: Those who had 0 to 4 CMRF accounted for 1,597 (45.7\%), 1,032 (29.5\%), 587 (16.8\%), 236 (6.7\%), and 44 (1.3\%) participants, respectively, in the Poisson distribution. Poisson regression analysis revealed that independent factors that contributed to the number of CMRF were age $(b=0.020, P<0.01)$, IPAQ $(b=-0.091, P<0.01)$, alcohol intake $(\mathrm{ml} /$ day $)(b=0.001, P=0.03)$, percentage of protein intake $(b=0.059, P=0.01)$, and total energy intake $(\mathrm{kcal})(\mathrm{b}=0.0001, \mathrm{P}<0.01)$. Furthermore, alcohol intake and its frequency had differential effects.
\end{abstract}

Conclusions: Alcohol intake, percent protein and total energy intake were positively associated, whereas drinking frequency and IPAQ were inversely associated, with the number of CMRF.

Keywords: alcohol, cardiometabolic risk factors, dietary intake, metabolic syndrome

\section{Background}

The prevalence of men with cardiometabolic risk factors (CMRF) is increasing in Japan. CMRF such as high blood pressure (BP), dyslipidemia, impaired glucose tolerance (IGT), and obesity tend to cluster together and it is closely related to insulin resistance [1-4]. The clustering of CMRF is known as metabolic syndrome (MetS), and is thought to be related to daily lifestyle habits, including nutrient intake, physical activity, smoking and alcohol consumption. As for the association between alcohol consumption and MetS, there have been several

\footnotetext{
* Correspondence: nakamury@kyoto-wu.ac.jp

'Cardiovascular Epidemiology, Kyoto Women's University, Kyoto, Japan

Full list of author information is available at the end of the article
}

cross-sectional studies. Some reported that the relation is inversely linear [5,6], J-shaped [7], or positively linear [8], whereas another found no relation $[9,10]$. Because alcohol consumption is associated with changes in consumption of several food groups and nutrients [11,12], an analysis of the relation between alcohol intake, as well as nutritional intake and CMRF, is needed. However, there are few comprehensive studies examining the relation between lifestyle factors and CMRF.

The objective of the present study was to examine cross-sectionally the relation between lifestyle habits including physical activity, smoking, dietary intake, alcohol intake and its frequency, and the number of CMRF

\section{C) Biomed Central}


in Japanese workers, and to find ways of preventing development of CMRF.

\section{Methods \\ Participants}

We analyzed baseline data from the high-risk and population strategy for occupational health promotion (HIPOP-OHP) study [13-16]. In brief, HIPOP-OHP was an interventional survey to establish a methodology for reducing cardiovascular disease (CVD) risk factors in the workplace. This study population consisted of fulltime workers at 12 large-scale companies (mostly, manufactures of electric appliances) throughout Japan. Each company had 500-1,000 employees. Researchers followed the data of CVD risk factors, lifestyle and consciousness about health based on nutrition, physical activity and smoking for four years [13-16]. This study was performed as part of the management of safety and health with the approval of the Safety Hygiene Committee at each company. Accordingly, all employees were enrolled in this study. However, participation was voluntary, and we explained there was no need for participants to answer the required questionnaire if they did not want to. Approval for the study was obtained from the Institutional Review Board of Shiga University of Medical Science for ethical issues (No. 10-16). During 1999-2000, baseline data were collected from 7,346 male and female workers aged from 19 to 69 years old.

There were 4,261 participants $(3,498$ men and 763 women) aged 19 to 69 years (mean \pm SD: $41.2 \pm 9.6$ years) who underwent a physical examination, a lifestyle survey and blood chemical examination. We excluded female participants because only about $20 \%$ of them were classified as drinkers; the amount of alcohol intake and its frequency were the important variables to examine in this study.

\section{Data collection and standardization}

Physical and laboratory data were standardized according to the manual of the HIPOP-OHP research group [13]. Briefly, after a 5 -min of silent rest measured by a sandglass, blood pressure was measured twice for each participant using the same automatic sphygmomanometer (Nihon Colin, BP-103iII) at each company, and the mean value was recorded. To measure the lipid concentrations in each participant, the company established a contract with a clinical laboratory; the blood testing was standardized through the US Cholesterol Reference Method Laboratory Network (CRMLN) [17]. The body mass index (BMI) was calculated as weight $(\mathrm{kg})$ divided by height squared $\left(\mathrm{m}^{2}\right)$.

Participants were asked about the type of, and time spent on, physical activities in their spare time for recreation, exercise or sport in the previous month. The physical activity of each participant was converted into MET-minutes per week ( $=$ MET level $\times$ minutes of activity/day $\times$ days per week) according to IPAQ [18], and participants were classified into four classes of physical activity: class 1: sedentary $(<600 \mathrm{MET}$-minutes per week), class 2: some activity ( $<1500$ but $\geq 600$ METminutes per week), class 3 : moderate activity $(<3000$ but $\geq 1500$ MET-minutes per week), or class 4: high ( $\geq$ 3000 MET-minutes per week). Participants were also asked about their type of work (mostly sitting, mostly standing, work including heavy physical activity for about one hour, work including heavy physical activity for about 2 hours, or other types).

Drinking habit for each subject was assessed by a questionnaire common to all companies [14]. The frequency of alcohol intake during a typical week and the total alcohol intake on each occasion were determined and used to calculate the alcohol intake per week. This value was then divided by 7 to obtain the average alcohol intake per day. Subjects were asked to estimate their alcohol intake based on gou, a traditional Japanese drinking unit corresponding to $23 \mathrm{~g}$ of ethanol. One gou is equivalent to 2 US and UK drink units, or $180 \mathrm{ml}$ of sake, and the ethanol content is roughly equivalent to that of a bottle of beer $(663 \mathrm{ml})$, two single shots of whiskey $(70 \mathrm{ml})$, a half glass of shochu $(110 \mathrm{ml})$, or 240 $\mathrm{ml}$ of wine. Drinkers were defined as those consuming more than 0.3 gou ( 0.6 drinks) per week ( $1 \mathrm{~g}$ of ethanol a day).

We used a semi-quantitative food frequency method. Participants were asked about their average intake of food and beverages during a period of one or two months prior to the interview using the questionnaire, which consisted of 52 questions. Nutrient intake was calculated using the INTERMAP food table [19]. The calories from alcohol were counted in the total energy intake. Although the original version of our semi-quantitative food frequency method with 94 closed-ended questions has been validated [20], the shorter version with 52 questions used in the present study, has not been validated. The method of shortening of the original version of our FFQ with 94 questions involved mainly condensing several questions into a fewer questions. For example, the original version asked "how often do you eat blue fish (, red fish, white fish) per week?" in three questions. The shorter version asked "how often do you eat blue fish, red fish, or white fish per week?" in one question. If a participant usually ate blue fish, red fish, and white fish once each per week, he/she answered such in the original version. For the shortened version, he/she was instructed to answer that he/she ate these kinds of fish 3 times per week. Similar condensations were taken place mainly in questions related to bread, noodles, and soybean products consumption. Thus, 
actually omission was not performed. Participants' energy intakes were between 500 and $5000 \mathrm{kcal} /$ day, and none of them were excluded from the study.

We defined four CMRF in this study according to previous studies [4,21,22] as follows: 1 ) high $\mathrm{BP}: \mathrm{SBP} \geq 130$ $\mathrm{mmHg}$, or DBP $\geq 85 \mathrm{mmHg}$,or the use of an antihypertensive drug; 2) dyslipidemia: either casual serum highdensity lipoprotein-cholesterol (HDL) concentration $<40$ $\mathrm{mg} / \mathrm{dl}$, or serum triglycerides (TG) concentration $\geq 150$ $\mathrm{mg} / \mathrm{dl}$, or on medication for dyslipidemia; 3) IGT: fasting blood glucose concentration $\geq 110 \mathrm{mg} / \mathrm{dl}$, or if less than 8 hours after meals $\geq 140 \mathrm{mg} / \mathrm{dl}$ ), or on medication for diabetes mellitus; 4) and obese: $\mathrm{BMI} \geq 25 \mathrm{~kg} / \mathrm{m}^{2}$.

\section{Statistical analysis}

The chi-square statistical test for nominal variables and one way analysis of variance for continuous variables were performed to assess whether there were significant differences among the groups stratified by the number of CMRF. To obtain trend P, the "contrast" option for analysis of variance was used for continuous variables, and Mantel-Haensel test for prevalence variables. Partial correlation coefficients among lifestyle factors (IPAQ classification, alcohol intake $[\mathrm{ml} /$ day] and its frequency [times/week], percentage energy intake of protein, fat, and carbohydrate [\% kcal], and total energy intake [mega calorie]) adjusted for age were obtained. Associations between the number of CMRF and lifestyle habits were analyzed by Poisson regression models, including age, IPAQ classification, type of work (mostly sitting, mostly standing, work including heavy physical activity for about one hour, work including heavy physical activity for about 2 hours, or other types; mostly sitting served as a reference), alcohol intake (ml/day), smoking (non-, past, or current smoker; non-smoker served as reference), percentage energy intake of protein, fat, and carbohydrate (\% kcal), and total energy intake ( $\mathrm{kcal})$, as independent variables. Also the association between drinking frequency and the number of CMRF was analyzed by similar Poisson regression models by quintile of alcohol intake among 2,029 male drinkers. All P values were two-sided, and $\mathrm{P}<0.05$ was considered significant. All analyses were performed using SAS version 9.2 for Windows (SAS Institute, Cary, NC).

\section{Results}

Among the 3,498 male participants, those who had 0 to 4 CMRF accounted for 1,597 (45.7\%), 1,032 (29.5\%), 587 (16.8\%), $236(6.7 \%)$, and $46(1.3 \%)$ men, respectively, in the Poisson distribution. The mean total intake energy was $2,118 \pm 465 \mathrm{kcal}$, and the percentage intakes of protein, fat and carbohydrate were $13.8 \pm 1.7,24.8 \pm 4.6$ and $60.6 \pm 5.6 \%$, respectively. Participants engaged in the following types of work: mostly sitting, mostly standing, work including heavy physical activity for about one hour, work including heavy physical activity for about 2 hours, or other types accounted for 49.3\%, 37.3\%, 5.2\%, $3.6 \%$ and $4.5 \%$, respectively. Characteristics of participants by group according to the number of CMRF are shown in Table 1. The mean SBP, DBP, BMI, alcohol intake, percentage of high BP, dyslipidemia, IGT, obese status, and of protein intake were higher among the groups with a higher number of CMRF. Mean IPAQ classification, alcohol drinking frequency, total energy intake, fat and percent carbohydrate intake, and prevalence of current smokers, were not different among the groups.

Results of partial correlation coefficients among lifestyle factors and CMRF adjusted for age are shown in Table 2. IPAQ was positively associated with percent protein and fat intakes, total energy intake; inversely associated with current smoking and percent carbohydrate intake. Amount of alcohol intake was positively associated with alcohol drinking frequency, percent protein and fat intakes, and current smoking; inversely with percent carbohydrate and total calorie intakes. Alcohol drinking frequency was positively associated with percent protein and fat intakes, and current smoking; inversely with percent carbohydrate and total calorie intakes. Percent protein intake was positively associated with percent fat intake; inversely with current smoking, percent carbohydrate and total energy intakes. Percent fat intake was positively associated with total calorie intake; inversely with smoking and percent carbohydrate intake. Percent carbohydrate intake was positively associated with smoking; inversely with total calorie intake.

Results of Poisson regression analysis are shown in Table 3. Independent factors that contributed to the number of CMRF were age (regression coefficient: $\mathrm{b}=$ 0.020, $\mathrm{P}<0.01)$, IPAQ $(\mathrm{b}=-0.091, \mathrm{P}<0.01)$, alcohol intake $(\mathrm{ml} /$ day $)(\mathrm{b}=0.001, \mathrm{P}=0.03)$, percentage of protein intake $(\% \mathrm{kcal})(\mathrm{b}=0.059, \mathrm{P}=0.01)$, and total energy intake $(\mathrm{kcal})(\mathrm{b}=0.0001, \mathrm{P}<0.01)$. The contribution of current smoking was not statistically significant $(\mathrm{b}=$ 0.089, $\mathrm{P}=0.05$ ).

Results of Poisson regression analysis on the association of alcohol drinking frequency with the number of CMRF by quintile of alcohol intake among 2,029 male drinkers are shown in Table 4. Cut off alcohol intake levels among the 5 groups were 12.5, 24.3, 39.7, and $62.5 \mathrm{ml} /$ day. There were about $400 \mathrm{men}$ in each group. Except for the lowest alcohol intake quintile group, drinking frequency was significantly inversely associated with the number of CMRF independent of the other factors.

\section{Discussion}

We found significant associations between percent protein intake, as well as total energy intake and the number 
Table 1 Characteristics of Participants by Group According to the Number of Cardiometabolic Risk Factors - HIPOPOHP Study

\begin{tabular}{|c|c|c|c|c|c|c|c|c|}
\hline CMRF No & 0 & 1 & 2 & 3 & 4 & Total & $P$ diff & $P$ trend \\
\hline Person N (\%) & $1597(45.7)$ & $1032(29.5)$ & $587(16.8)$ & $236(6.7)$ & $46(1.3)$ & 3498 & - & \\
\hline Age (year) & $39.1 \pm 9.6$ & $41.8 \pm 9.5$ & $43.8 \pm 8$ & $43.4 \pm 9.4$ & $46.3 \pm 7.3$ & $41.1 \pm 9.6$ & $<0.01$ & $<0.01$ \\
\hline $\mathrm{SBP}(\mathrm{mmHg})$ & $110.2 \pm 9.9$ & $121.5 \pm 14.7$ & $130.8 \pm 15.8$ & $140.7 \pm 14.1$ & $142.4 \pm 15.1$ & $119.5 \pm 16.3$ & $<0.01$ & $<0.01$ \\
\hline $\mathrm{DBP}(\mathrm{mmHg})$ & $67.3 \pm 7.6$ & $75.0 \pm 10.5$ & $81.6 \pm 11.1$ & $87.9 \pm 10.1$ & $89.8 \pm 8.2$ & $73.7 \pm 11.6$ & $<0.01$ & $<0.01$ \\
\hline High BP (\%) & 0 & 31.8 & 60.3 & 94.1 & 100 & 27.2 & $<0.01$ & $<0.01$ \\
\hline Dyslipidemia (\%) & 0 & 41.6 & 63.5 & 89.0 & 100 & 30.2 & $<0.01$ & $<0.01$ \\
\hline IGT (\%) & 0 & 5.7 & 15.7 & 27.1 & 100 & 7.5 & $<0.01$ & $<0.01$ \\
\hline BMI $\left(\mathrm{kg} / \mathrm{m}^{2}\right)$ & $21.5 \pm 1.9$ & $23.2 \pm 2.5$ & $25.6 \pm 3.0$ & $27.2 \pm 2.9$ & $27.7 \pm 1.9$ & $23.2 \pm 3.0$ & $<0.01$ & $<0.01$ \\
\hline Obese (\%) & 0 & 20.9 & 60.5 & 89.8 & 100 & 23.7 & $<0.01$ & $<0.01$ \\
\hline IPAQ & $1.4 \pm 0.7$ & $1.3 \pm 0.7$ & $1.3 \pm 0.6$ & $1.3 \pm 0.7$ & $1.3 \pm 0.5$ & $1.3 \pm 0.7$ & 0.21 & 0.25 \\
\hline Current-Smoking (\%) & 53.8 & 56.8 & 56.4 & 54.7 & 52.2 & 55.1 & 0.58 & 0.44 \\
\hline Alcohol (ml/day) & $20.9 \pm 30.3$ & $24.2 \pm 33.4$ & $27.9 \pm 36.5$ & $23.2 \pm 30.6$ & $36.3 \pm 40.4$ & $23.4 \pm 32.6$ & $<0.01$ & $<0.01$ \\
\hline Alcohol (times/week) & $2.9 \pm 2.9$ & $3.0 \pm 3.0$ & $3.1 \pm 3.0$ & $2.9 \pm 2.8$ & $3.1 \pm 2.8$ & $3.0 \pm 2.9$ & 0.71 & 0.78 \\
\hline Total energy (kcal) & $2143 \pm 449$ & $2067 \pm 461$ & $2110 \pm 484$ & $2196 \pm 508$ & $2120 \pm 481$ & $2118 \pm 465$ & $<0.01$ & 0.56 \\
\hline Protein (\%kcal) & $13.6 \pm 1.6$ & $13.9 \pm 1.8$ & $13.9 \pm 1.6$ & $14.0 \pm 1.7$ & $14.6 \pm 1.9$ & $13.8 \pm 1.7$ & $<0.01$ & $<0.01$ \\
\hline Fat (\%kcal) & $25.2 \pm 4.5$ & $24.7 \pm 4.7$ & $24.3 \pm 4.7$ & $24.7 \pm 4.7$ & $24.9 \pm 5.1$ & $24.8 \pm 4.6$ & $<0.01$ & 0.66 \\
\hline Carbohydrate (\%kcal) & $60.5 \pm 5.4$ & $60.6 \pm 5.8$ & $60.9 \pm 5.6$ & $60.5 \pm 5.7$ & $59.3 \pm 6.4$ & $60.6 \pm 5.6$ & 0.35 & 0.15 \\
\hline
\end{tabular}

Characteristics of participants by group according to the number of cardiometabolic risk factors (CMRF) in 3,498 Japanese men in 1999-2000 are shown. The chisquare statistical test for nominal variables and one way analysis of variance for continuous variables were performed to assess whether there were significant differences among the groups stratified by the number of CMRF. To obtain trend $P$, the "contrast" option for analysis of variance was used for continuous variables, and Mantel-Haensel test for prevalence variables. We defined four CMRF in this study as follows: 1 ) high BP: SBP $\geq 130 \mathrm{mmHg}$, or DBP $\geq 85 \mathrm{mmHg}, \mathrm{or}$ the use of an antihypertensive drug; 2) dyslipidemia: $\mathrm{HDL}<40 \mathrm{mg} / \mathrm{dl}$, or TG $\geq 150 \mathrm{mg} / \mathrm{dl}$, or on medication for dyslipidemia; 3)IGT: fasting blood sugar concentration $\geq 110 \mathrm{mg} / \mathrm{dl}$, or if less than 8 hours after meals $\geq 140 \mathrm{mg} / \mathrm{dl}$ ), or on medication for diabetes mellitus; 4 ) obesity: defined as BMI $\geq 25 \mathrm{~kg} / \mathrm{m}^{2}$.CMRF $=$ cardiometabolic risk factors, $\mathrm{SBP}=$ systolic blood pressure, $\mathrm{DBP}=$ diastolic blood pressure, IGT $=$ impaired glucose tolerance, $\mathrm{BMI}=$ body mass index, IPAQ $=$ International Physical Activity Questionnaire classification.

of CMRF. The latter finding was expected, but the former finding was rather unexpected in the context of recent favorable results regarding low carbohydrate, high protein diets $[23,24]$. In this study, the average total energy intake was $2,118 \mathrm{kcal}$, and the percentages of protein, fat and carbohydrate of total energy intake were 13.8, 24.8 and $60.6 \%$, respectively. These values are consistent with the results of the Japanese National Health and Nutrition Examination Survey [25], which reported that the average total energy intake of men with age $\geq 20$ years was 2,173 $\pm 605 \mathrm{kcal}$. A study by Pan et al. in a population-based sample of 2,811 Chinese middle-aged and elderly, suggested habitual soy protein intake in men, but not in women, was associated with the risk of MetS [26]. Azadbakht et al. found that increased red meat consumption was cross-sectionally associated with greater risk of MetS and inflammation in 482 Tehrani females aged 40-60 years [27]. Thus, the results of some studies agreed with ours. Further research is therefore needed incorporating nutritional analyses.

Table 2 Partial Correlation Coefficients among Lifestyle Factors and Cardiometabolic Risk Factors Adjusted for Age HIPOP-OHP Study

\begin{tabular}{|c|c|c|c|c|c|c|c|}
\hline & IPAQ & $\begin{array}{c}\text { Alcohol } \\
\text { intake (ml) }\end{array}$ & $\begin{array}{c}\text { Alcohol intake } \\
\text { (times/week) }\end{array}$ & $\begin{array}{c}\text { Protein(\% } \\
\text { energy) }\end{array}$ & $\begin{array}{c}\text { Total fat (\% } \\
\text { energy) }\end{array}$ & $\begin{array}{c}\text { Carbohydrate (\% } \\
\text { energy) }\end{array}$ & $\begin{array}{c}\text { Total energy intake } \\
\text { (calories) }\end{array}$ \\
\hline Alcohol intake (ml) & -0.003 & 1.000 & & & & & \\
\hline $\begin{array}{l}\text { Alcohol intake } \\
\text { (times/week) }\end{array}$ & -0.014 & $0.719^{* *}$ & 1.000 & & & & \\
\hline Protein (\% energy) & $0.095^{* *}$ & $0.162^{* *}$ & $0.140^{* *}$ & 1.000 & & & \\
\hline Total fat (\% energy) & $0.049^{* *}$ & $0.108^{* *}$ & $0.127^{* *}$ & $0.411^{* *}$ & 1.000 & & \\
\hline $\begin{array}{l}\text { Carbohydrate (\% } \\
\text { energy) }\end{array}$ & $-0.057^{* *}$ & $-0.151^{* *}$ & $-0.159^{* *}$ & $-0.675^{* *}$ & $-0.926^{* *}$ & 1.000 & \\
\hline $\begin{array}{l}\text { Total energy intake } \\
\text { (calories) }\end{array}$ & $0.059^{* *}$ & $-0.064^{* *}$ & $-0.063^{* *}$ & $-0.042^{*}$ & $0.210^{* *}$ & $-0.135^{* *}$ & 1.000 \\
\hline Smoking & $-0.088^{* *}$ & $0.122^{* *}$ & $0.076^{* *}$ & $-0.088^{* *}$ & $-0.071^{* *}$ & $0.066^{* *}$ & -0.023 \\
\hline
\end{tabular}

Partial correlation coefficients among the lifestyle factors and metabolic risk factors adjusted for age are shown. ${ }^{*} \mathrm{P}<0.05,{ }^{* *} \mathrm{P}<0.01$.

IPAQ = International Physical Activity Questionnaire classification. 
Table 3 Independent Factors that Contributed to the Number of Cardiometabolic Risk Factors - Results of Poisson Regression Analysis

\begin{tabular}{lcc}
\hline Variable & Regression coefficient & $\mathbf{P}$ \\
\hline Age (year) & 0.020 & $<0.01$ \\
IPAQ & -0.091 & $<0.01$ \\
Current smoking & 0.089 & 0.05 \\
Alcohol intake (ml/day) & 0.001 & 0.03 \\
Protein (\%kcal) & 0.059 & 0.01 \\
Fat (\%kcal) & -0.008 & 0.62 \\
Carbohydrate (\%kcal) & 0.007 & 0.67 \\
Total energy intake (kcal) & 0.0001 & $<0.01$ \\
\hline
\end{tabular}

Results of analysis by Poisson regression models on associations between the number of CMRF and lifestyle are shown. Covariates included are shown in this Table plus type of work with regard to occupational physical activity (mostly sitting, mostly standing, work including heavy physical activity for about one hour, work including heavy physical activity for about 2 hours, or other types; mostly sitting served as a reference). IPAQ = International Physical Activity Questionnaire classification

We found a significant positive association between alcohol consumption and the number of CMRF, whereas there was a significant inverse association between frequency of alcohol intake and the number of CMRF except for the lowest alcohol intake quintile group. Thus, when the amount of alcohol intake was relatively moderate, a higher drinking frequency was associated with a lower number of CMRF. Several crosssectional studies have reported an association between alcohol drinking and MetS prevalence. However, they showed inconsistent findings [5-10]. Dixon et al. showed that light to moderate alcohol consumption had a favorable effect on metabolic risk factors and insulin resistance in severely obese patients with $\mathrm{BMI}>35 \mathrm{~kg} / \mathrm{m}^{2}$ [6]. However, in the Atherosclerosis and Insulin Resistance study of 391 healthy 58-y-old men, no significant difference was found in alcohol consumption between the subjects with MetS and those without risk factors [10]. Yoon et al. who studied 7,962 Korean men and women and found that alcohol consumption had a significant inverse relation with the odds ratio for low HDL cholesterol in all alcohol groups; however, an increasing dose-response relation was found between alcohol consumption and the odds ratio for MetS [7]. Fan et al. studied patterns of alcohol consumption and MetS, and found that the usual daily quantity of alcohol intake was positively associated with MetS, and that the frequency of binge drinking was also positively associated with MetS [8]. Thus, our findings are basically consistent with those of Fan et al.

In the present study, we found a significant inverse association between physical activities assessed by IPAQ and the number of CMRF among mostly middle-aged male participants. There are not many studies on the association between physical activity and CMRF or MetS. Dalacrote et al. studied 362 community-dwelling elderly people in southern Brazil, and found no significant association between MetS and the IPAQ level of physical activity in men and women [28]. In a study by Ekelund et al. in a population-based sample of 3,193 European youths, lower physical activity was independently associated with MetS after adjustment for sex, age, and other covariates [29], Hahn et al. in a population-based study of 1,653 elderly participants also found that intense physical activities significantly reduced the odds of having MetS [30]. Thus, studies with a larger number of participants found similar results to ours.

The strengths of our study include being populationbased, large-scale, and multi-site with highly standardized methods. Since the study included men of a broad range of ages, findings are likely to be generalizable to middle-aged Japanese men. The study was limited by its cross-sectional design. Second, we did not measure waist circumference (WC). Although the measurement of WC is widely advocated as a simple anthropometric marker of health risk, there remains no uniformly accepted protocol. Mason et al. showed that the measurement site had an influence on the apparent prevalence of abdominal obesity $(>88 / 102 \mathrm{~cm})$, ranging from 23 to $34 \%$ in men and 31 to $55 \%$ in women [31]. Panoulas et al. showed a significant inter-operator variability

Table 4 Association of Alcohol Drinking Frequency with the Number of Cardiometabolic Risk Factors by Quintile of Alcohol Intake Among 2,029 Male Drinkers - Results of Poisson Regression Analysis

\begin{tabular}{cccc}
\hline Alcohol intake (range, $\mathbf{m l} /$ day) & Person $\mathbf{N}$ & Regression coefficient of drinking frequency & $\mathbf{P}$ \\
\hline $1.25-12.5$ & 405 & -0.007 & 0.87 \\
$12.8-24.3$ & 406 & -0.074 & $<0.01$ \\
$24.5-39.7$ & 408 & -0.13 & $<0.01$ \\
$39.9-62.5$ & 393 & -0.109 & $<0.01$ \\
$62.7-250.0$ & 393 & -0.086 & 0.047 \\
\hline
\end{tabular}

Results of analysis by Poisson regression models on association between alcohol drinking frequency and the number of CMRF by quintile of alcohol intake among 2,029 male drinkers are shown. Covariates included besides alcohol intake frequency were age, IPAQ classification, type of work (mostly sitting, mostly standing, work including heavy physical activity for about one hour, work including heavy physical activity for about 2 hours, or other types; mostly sitting served as a reference), smoking (non-, past, or current smoker; non-smoker served as a reference), percentage energy intake of protein, fat, and carbohydrate (\% $\mathrm{kcal})$, and total energy intake (kcal). IPAQ = International Physical Activity Questionnaire classification. 
that could lead to disagreement among operators regarding the presence of central obesity in $9 \%$ of the patients [32]. We showed in a population based study that BMI and WC correlated very well in men and women, and that BMI could be used instead of WC in a study when the latter was not available [33]. Third, we did not have a validation study for our semi-quantitative food frequency method. Although the original version of our semi-quantitative food frequency method with 94 closed-ended questions has been validated [20], the shorter version with 52 questions used in the present study, has not been validated. The method of shortening of the original version questions involved mainly condensing several questions into a fewer questions. Thus, actually omission was not performed. As indicated above, our nutritional values were consistent with the results of the Japanese National Health and Nutrition Examination Survey [25]. We think our shorter version was able to capture almost all the components of the diet. Forth, we cannot say how many criteria a person needs to have in order to have cardiometabolic syndrome. For this purpose, we may better to have evidence from prospective studies. We cannot obtain such evidence, since this study is a cross-sectional study. However, previous studies have shown that separate components of cardiometabolic syndrome are associated with a higher risk of coronary heart disease and stroke. Thus, we think prevention from developing each component is more important than dichotomizing people into two groups with and without the syndrome and preventing development of the syndrome.

The messages we obtained from our present study are: in order to prevent from developing each component of CMRF, we recommend to participate in physical activities and reduce intake of total energy and not to take a large amount of alcohol at a time.

In conclusion, alcohol intake, percent protein and total energy intakes were positively associated whereas drinking frequency and IPAQ were inversely associated, with the number of CMRF.

\section{List of abbreviations}

BMI: body mass index; BP: blood pressure; CMRF: cardiometablic risk factors; CVD: cardiovascular disease; DBP: diastolic blood pressure; HDL: high-density lipoprotein-cholesterol; HIPOP-OHP: the high-risk and population strategy for occupational health promotion; IGT; impaired glucose tolerance; IPAQ: the International Physical Activity Questionnaire; MetS: metabolic syndrome; SBP: systolic blood pressure; TG: triglycerides;

\section{Acknowledgements}

This study was funded by research grants from the Ministry of Health and Welfare of Japan (H10-12, No. 063, Research on Health Services, Health Sciences Research Grants and H13, No. 010, Medical Frontier Strategy Research, Health Sciences Research Grants), the Ministry of Health, Labor, and Welfare of Japan (H14-15, No. 010, Clinical Research for Evidence-Based Medicine, Health, and Labor Sciences Research Grants), and the Japan Arteriosclerosis Prevention Fund 2004.
We thank Toshimi Yoshida of the Department of Health Science, Shiga University of Medical Science, for her excellent clerical support during this research.

Investigators and members of the research group are listed in the appendix of reference 14 .

\section{Author details}

${ }^{1}$ Cardiovascular Epidemiology, Kyoto Women's University, Kyoto, Japan. ${ }^{2}$ Department of Health Science, Shiga University of Medical Science, Otsu, Japan. ${ }^{3}$ The First Institute of Health Service, Japan Anti-Tuberculosis Association, Tokyo, Japan. ${ }^{4}$ Department of Medical Statistics, Shiga University of Medical Science Otsu, Japan. ${ }^{5}$ Department of Health and Nutrition, Tsukuba International Junior College, Tsuchiura, Japan. ${ }^{6}$ Department of Food Science and Nutrition, Graduate School of Human Life Science, Osaka City University, Osaka, Japan. ${ }^{7}$ Department of Health Sciences, Interdisciplinary Graduate School of Medicine and Engineering, University of Yamanashi, Chuo, Japan. ${ }^{8}$ Department of Public Health, Kinki University School of Medicine, Osaka-sayama, Japan. ${ }^{9}$ Department of Preventive Medicine and Public Health, School of Medicine, Keio University, Tokyo, Japan.

\section{Authors' contributions}

KS participated in analyzing and interpreting the data, and drafting and preparing the manuscript, YN participated in designing and conducting the study, interpreting the data, and editing the draft. $\Pi$, and TO participated in managing the dataset and analyzing the data. YM participated in statistical consultation, while ONO, NC, KY, JT and ToT participated in developing and conducting the nutritional survey. $\mathrm{TO}$, and $\mathrm{KM}$ participated in the physical activity survey, and $\mathrm{AO}$ participated designing and conducting the study. $\mathrm{HU}$ was the principal investigator, designing and conducting the study and analyzing and interpreting the data.

All authors read and approved the final manuscript.

\section{Competing interests}

The authors declare that they have no competing interests.

Received: 3 June 2011 Accepted: 14 November 2011

Published: 14 November 2011

\section{References}

1. Bhatt DL, Steg PG, Ohman EM, Hirsch AT, Ikeda Y, Mas JL, Goto S, Liau CS, Richard AJ, Röther J, Wilson PW: International prevalence, recognition, and treatment of cardiovascular risk factors in outpatients with atherothrombosis. JAMA 2006, 295:180-189.

2. Reaven GM: Role of insulin resistance in human disease. Diabetes 1988 , 37:1595-1607.

3. Meigs JB, D'Agostino RBS, Wilson PW, Cupples LA, Nathan DM, Singer DE: Risk variable clustering in the insulin resistance syndrome. The Framingham Offspring Study. Diabetes 1997, 46:1594-1600.

4. Executive Summary of the Third Report of the National Cholesterol Education Program (NCEP) Expert Panel on Detection, Evaluation, and Treatment of High Blood Cholesterol in Adults (Adult Treatment Panel III). JAMA 2001, 285:2486-2497.

5. Park YW, Zhu S, Palaniappan L, Heshka S, Carnethon MR, Heymsfield SB: The metabolic syndrome: prevalence and associated risk factor findings in the US population from the Third National Health and Nutrition Examination Survey, 1988-1994. Arch Intern Med 2003, 163:427-36.

6. Dixon JB, Dixon ME, O'Brien PE: Alcohol consumption in the severely obese: relationship with the metabolic syndrome. Obes Res 2002, 10:245-52.

7. Yoon YS, Oh SW, Baik HW, Park HS, Kim WY: Alcohol consumption and the metabolic syndrome in Korean adults: the 1998 Korean National Health and Nutrition Examination Survey. Am J Clin Nutr 2004, 80:217-24.

8. Fan AZ, Russell M, Naimi T, Li Y, Liao Y, Jiles R, Mokdad AH: Patterns of alcohol consumption and the metabolic syndrome. J Clin Endocrinol Metab 2008, 93:3833-8.

9. Lee WY, Jung CH, Park JS, Rhee EJ, Kim SW: Effects of smoking, alcohol, exercise, education, and family history on the metabolic syndrome as defined by the ATP III. Diabetes Res Clin Pract 2005, 67:70-7.

10. Goude D, Fagerberg B, Hulthe J: Alcohol consumption, the metabolic syndrome and insulin resistance in 58-year-old clinically healthy men (AIR study). Clin Sci (Lond) 2002, 102:345-52 
11. Yeomans MR: Effects of alcohol on food and energy intake in human subjects: evidence for passive and active over-consumption of energy. Br J Nutr 2004, 92(Suppl 1):S31-4.

12. Yeomans MR, Caton S, Hetherington MM: Alcohol and food intake. Curr Opin Clin Nutr Metab Care 2003, 6:639-44.

13. Okamura T, Tanaka T, Babazono A, Yoshita K, Chiba N, Takebayashi T, Nakagawa H, Yamato H, Miura K, Tamaki J, Kadowaki T, Okayama A, Ueshima $\mathrm{H}$ : The high-risk and population strategy for occupational health promotion (HIPOP-OHP) study: study design and cardiovascular risk factors at the baseline survey. J Hum Hypertens 2004, 18:475-85.

14. Okamura T, Tanaka T, Yoshita K, Nakagawa H, Yamato H, Yoshita K, Kadowaki T, Okayama A, Ueshima H: Specific alcoholic beverage and blood pressure in a middle-aged Japanese population: the high-risk and population strategy for occupational health promotion (HIPOP-OHP) study. J Hum Hypertens 2004, 18:9-16.

15. Naito M, Nakayama T, Okamura T, Miura K, Yanagita M, Fujieda Y, Kinoshita F, Naito Y, Nakagawa H, Tanaka T, Ueshima H: Effect of a 4-year workplace-based physical activity intervention program on the blood lipid profiles of participating employees: the high-risk and population strategy for occupational health promotion (HIPOP-OHP) study. Atherosclerosis 2008, 197:784-90

16. Tamura U, Tanaka T, Okamura T, Kadowaki T, Yamato H, Tanaka H, Nakamura M, Okayama A, Ueshima H, Yamagata Z: Changes in weight, cardiovascular risk factors and estimated risk for coronary heart disease following smoking cessation in Japanese male workers: HIPOP-OHP Study. J Atheroscler Throm 2010, 17:12-20.

17. Nakamura M, Sato S, Shimamoto T: Improvement in Japanese clinical laboratory measurements of total cholesterol and $\mathrm{HDL}$-cholesterol by the US Cholesterol Reference Method Laboratory Network. J Atheroscler Thromb 2003, 10:145-53.

18. Craig CL, Marshall AL, Sjostrom M, Bauman AE, Booth ML, Ainsworth BE, Pratt M, Ekelund U, Yngve A, Sallis JF, Oja P: The International Physical Activity Questionnaire (IPAQ): A comprehensive reliability and validity study in twelve countries. Med Sci Sports Exerc 2003, 35:1381-95.

19. Schakel SF, Dennis BH, Wold AC, Rana Conway, Zhao L, Okuda N, Okayama A, Moag-Stahlberg A, Robertson C, Van Heel N, Buzzard IM, Stamler J: Enhancing data on nutrient composition of foods eaten by participants in the INTERMAP study in China, Japan, the United Kingdom, and the United States. J Food Comp Anal 2003, 16:395-408.

20. Chiba N, Okuda N, Okayama A, Kadowaki T, Ueshima H: Development of a food frequency and quantity method for assessing dietary habits of Japanese individuals-comparison with results from $24 \mathrm{hr}$ recall dietary survey. J Atheroscler Thromb 2008, 15:324-33.

21. Alberti KG, Zimmet P, Shaw J: IDF Epidemiology Task Force Consensus Group. The metabolic syndrome-a new worldwide definition. Lancet 2005, 366:1059-62.

22. International Diabetes Federation: The IDF consensus worldwide definition of the metabolic syndrome.[http://www.idf.org/webdata/docs/ MetS_def_update2006.pdf].

23. Gardner CD, Kiazand A, Alhassan S, Kim S, Stafford RS, Balise RR, Kraemer HC, King AC: Comparison of the Atkins, Zone, Ornish, and LEARN diets for change in weight and related risk factors among overweight premenopausal women: the A TO Z Weight Loss Study: a randomized trial. JAMA 2007, 297:969-77.

24. Shai I, Schwarzfuchs D, Henkin Y, Shahar DR, Witkow S, Greenberg I, Golan R, Fraser D, Bolotin A, Vardi H, Tangi-Rozental O, Zuk-Ramot R, Sarusi B, Brickner D, Schwartz Z, Sheiner E, Marko R, Katorza E, Thiery J, Fiedler GM, Blüher M, Stumvoll M, Stampfer MJ: Weight loss with a lowcarbohydrate, Mediterranean, or low-fat diet. N Engl J Med 2008, 359:229-41.

25. Ministry of Health and Welfare, Japan: The National Nutrition Survey in Japan, 1992 (in Japanese) Daiichi Shopping (Tokyo, Japan). 1992.

26. Pan A, Franco OH, Ye J, Demark-Wahnefried W, Ye X, Yu Z, Li H, Lin X: Soy protein intake has sex-specific effects on the risk of metabolic syndrome in middle-aged and elderly Chinese. J Nutr 2008, 138:2413-2421.

27. Azadbakht L, Esmaillzadeh A: Red meat intake is associated with metabolic syndrome and the plasma C-reactive protein concentration in women. J Nutr 2009, 139:335-339.

28. Dalacorte RR, Reichert CL, Vieira JL: Metabolic syndrome and physical activity in southern Brazilian community-dwelling elders: a populationbased, cross-sectional study. BMC Public Health 2009, 9:25.
29. Ekelund U, Anderssen S, Andersen LB, Riddoch CJ, Sardinha LB, Luan J, Froberg K, Brage S: Prevalence and correlates of the metabolic syndrome in a population-based sample of European youth. AM J Clin Nutr 2009, 89:90-96.

30. Hahn V, Halle M, Schmidt-Trucksäss A, Rathmann W, Meisinger C, Mielck A Physical activity and the metabolic syndrome in elderly German men and women: results from the population-based KORA survey. Diabetes Care 2009, 32:511-3.

31. Mason C, Katzmarzyk PT: Variability in waist circumference measurements according to anatomic measurement site. Obesity 2009, 17:1789-1795.

32. Panoulas VF, Ahmad N, Fazal AA, Kassamali RH, Nightingale P, Kitas GD, Labib M: The inter-operator variability in measuring waist circumference and its potential impact on the diagnosis of the metabolic syndrome. Postgrad Med J 2008, 84:344-347.

33. Nakamura Y, Turin TC, Kita Y, Tamaki S, Tsujita Y, Kadowaki T, Murakami Y, Okamura $\mathrm{T}$, Ueshima $\mathrm{H}$ : The associations of obesity measures with the metabolic risk factors in a community-based population in Japan. Circ $J$ 2007, 71:776-781.

doi:10.1186/1758-5996-3-30

Cite this article as: Katano et al.: Relationship between Dietary and Other Lifestyle Habits and Cardiometabolic Risk Factors in Men.

Diabetology \& Metabolic Syndrome 2011 3:30.

\section{Submit your next manuscript to BioMed Central and take full advantage of:}

- Convenient online submission

- Thorough peer review

- No space constraints or color figure charges

- Immediate publication on acceptance

- Inclusion in PubMed, CAS, Scopus and Google Scholar

- Research which is freely available for redistribution

Submit your manuscript at www.biomedcentral.com/submit
C Biomed Central 